5. Lirror due to products of iermentation in old or spoiled samples is aroided by boiling before precipitating.

6. With the average nolsture content of $10-12$ per cent. for sugars, and $3,3-3,5$ per cent. for sirups, the lead values are in each case on about the sane anount of dry substance. It might be a good plan to make a moisture determination on each sample and calculate the loal watur to "dry" substance."

BUFFALO TATORATORY:

\title{
TYPEWRITER CARBON PAPERS.
}

\author{
JY A. M. DoYts.
}

Received June 20, rgos,

Iypewriter carbon papers are much used in the departments of the government and for this reason an investigation into their qualities was made by the Contracts I,aboratory of the Bureau of Chemistry. The paper fomndation was tested for tensile strength, length and width; stretch under strain, both length and width; weight, inked and clean; thickness of inked paper; kind of pulp used and degree of beat. 'The ink, as distinct from the paper, was separated into its constituents of oil or wax, dye and pigments, and moisture and ash were determined. The written matter was rated on a scale of ten and was also subjected to sunlight and solubility tests.

of the twenty eight samples examined, five were copy papers and the others record. Copy papers included black, blue, purple and green, all of stanclarel weight; record papers consisted of black, blue and purple; full-inkel and semi-inked: standarl weight, light weight and feather weight. lables 1. II and III represent the three classes of results. In lable I the physical tests have been arranged according to the weight of the paper, as described by the manufacturer, while in Tables II and III they are divided lisst into record and copy: then according to colorblack, blue and purple, in the order named; and finally, within each group accordiug to weight, from standard to feather weight.

\section{Discussion of Results.}

A comparison of the figures for the weiglit of the paper per square centimeter indicates that No. 2202 shonld be classed with light weight papers, Nos. 2200, 2293, 2294, 2,301 and 2,302 with standard weight, and Nos. 2300, 2.36 and 2,382 with the light weight: but otherwise these papers, gromped ats indicater by the mantafacturets on the label of the packace, follow chosty coltain woight linits. Inked papers average

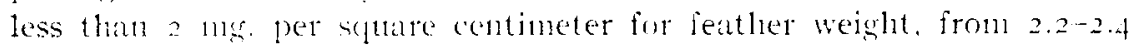
ng. for light weight and a little less llan $;$ mo. For standard weight. the cleaned papers, free of ink. weigh less than I nug. for feather weight, 


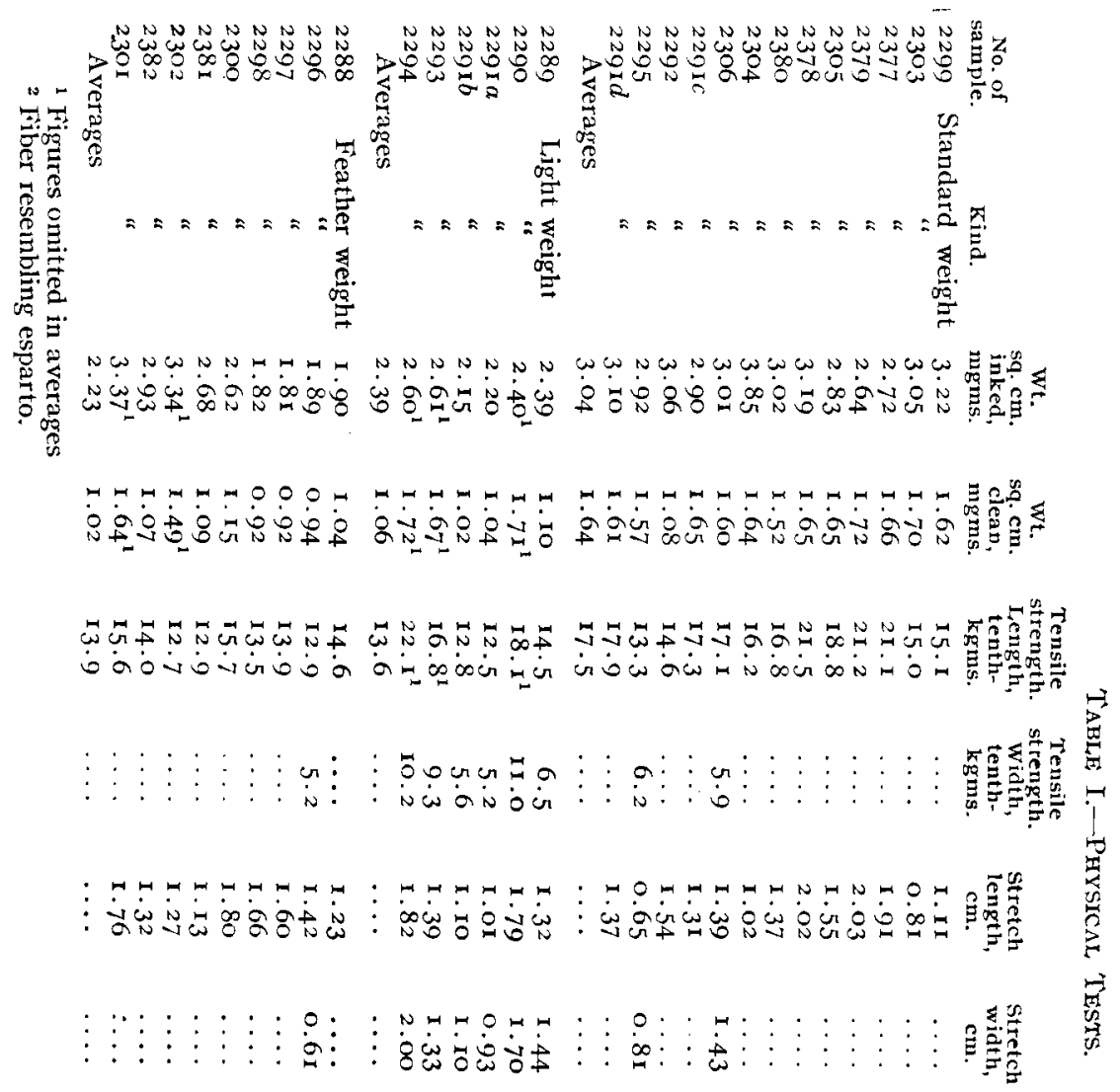

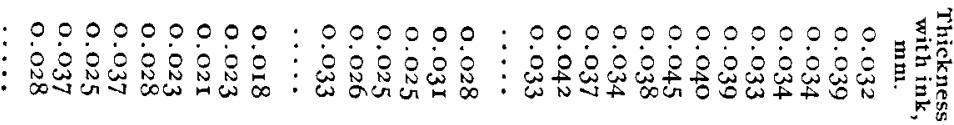

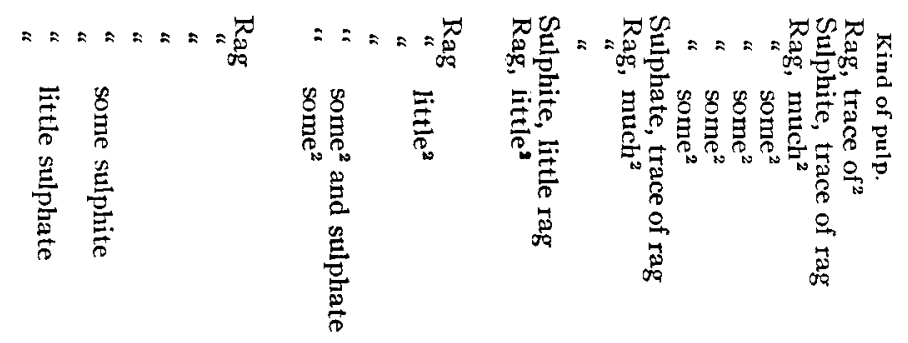

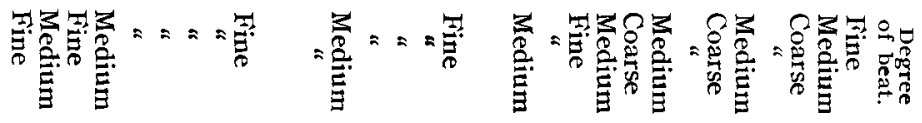


between I.O and I. I mg. for light weight and from I.6-1.7 for standard weight papers.

Mr. B. J. Howard, Chief of the Microscopic Laboratory, made all of the tests for thickness, kind of pulp and degree of beat. Irom the last column of the table it may be seen that the degree of beat of the pulp is generally coarse or medium in standard weight material and for the light and feather weight is usually fine or medium. The kind of pulp is not uniform, being either all rag, all sulphite, mixed rag and sulphite or mixed rag with a kind of fiber "somewhat resembling esparto, though without its characteristic structure." These fibers Mr. Howard found it "impossible to determine, as they were so thoroughly beaten as to almost destroy their identity. It was found impossible to distinguish between linen and cotton fibers for the same reason, and both together are classified as rag." In general, those papers containing rag fibers together with the undetermined fiber like esparto gave the highest tests for tensile strength and stretch. The thickness of the papers measured in thousandths of a millimeter showed decided average difierences for the three weights, ranging from twenty for feather weight to twenty-five or thirty for light weight and from thirty-five to forty for standard weight.

Marked difierences between papers of the same class were brought out by the tensile strength and stretch tests. A Schopper paper-testing machine adapted for weights from one to fifty kilograms was found to be too heavy, so a pendulum exercising one-fifth the strain was substituted on the same machine and all of the tensile strength tests were made with this smaller weight. The figures, as reported in the table, are, however, recalculated so as to be comparable with those obtained on the standard Schopper machine. In a lew instances the tests were applied across fiber, as shown in columns on the table. The strip of material employed for the tests was $18 \mathrm{~cm}$. in length and $1.5 \mathrm{~cm}$. in width-the regulation size for this machine.

From the number of samples compared and the fact that their age was not known, it is difficult to trace any general rule with regard to the relation of thickness, kind of pulp and degree of beat with the tensile strength and stretch. Neither does the weight of the paper have the direct influence that might be expected. It is certain, however, that standard weight papers of approximately $1.65 \mathrm{mg}$. weight per sq. cm. should not be of a strength less than i 8 tenth-kilograms (the unit of weight used on the table); nor have a stretch of less than $2 \mathrm{~cm}$. in an $18 \mathrm{~cm}$. strip. Sinilarly, for light and feather weight papers averaging I $\mathrm{mg}$. weight per sq. cm., the strength and stretch should not fall below I4 tenth-kilograms and $1.5 \mathrm{~cm}$. respectively. These tests bear directly on the wearing qualities of the paper and are valuable in making an estimate of its length of service. 
TYPEWRITER CARBON PAPERS.

TABLE II.-ChEMICAL Tests.

RECORd PAPERS: BLACK.

\begin{tabular}{|c|c|c|c|c|c|c|c|c|}
\hline No. & $\begin{array}{l}\text { Moisture. } \\
\text { Per cent. }\end{array}$ & $\begin{array}{l}\text { Ash. } \\
\text { Per cent. }\end{array}$ & $\begin{array}{l}\text { Carbon. } \\
\text { Per cent. }\end{array}$ & $\begin{array}{c}\text { Dye. } \\
\text { Per cent. }\end{array}$ & $\begin{array}{l}\text { Pigment. } \\
\text { Percent. }\end{array}$ & $\begin{array}{l}\text { Wax. } \\
\text { Per cent. }\end{array}$ & $\begin{array}{l}\text { Ink. } \\
\text { Per cent. }\end{array}$ & $\begin{array}{l}\text { Paper. } \\
\text { Per cent }\end{array}$ \\
\hline 2288 & 4.03 & 3.92 & $3 \cdot 31$ & 0.46 & $5 \cdot 30$ & $31 \cdot 34$ & $44 \cdot 5^{8}$ & $55 \cdot 42$ \\
\hline 2289 & 4.08 & 8.60 & 6.65 & 2.45 & I 2. 79 & 29.10 & 55.08 & 44.92 \\
\hline 2290 & 5.25 & $4 \cdot 50$ & 2.59 & 0.50 & 6.07 & 15.18 & 29.57 & 70.43 \\
\hline 2377 & $4 \cdot 42$ & 5.69 & 6.81 & 0.72 & $8.8 \mathrm{I}$ & 18.86 & 39.19 & 60.81 \\
\hline 2379 & $4 \cdot 4 \mathrm{I}$ & 5.88 & 6.28 & 0.83 & $8.5^{8}$ & $15 \cdot 77$ & 35.14 & 64.86 \\
\hline 2381 & 2.98 & 9.83 & 9.89 & 0.77 & $14 \cdot 38$ & 31.27 & 59.47 & 40.53 \\
\hline $2291 a$ & $3 \cdot 73$ & 5.20 & $5 \cdot 53$ & 1.20 & 8.30 & 31.87 & 50.92 & 49.08 \\
\hline 22916 & $3 \cdot 94$ & 5.20 & 5.63 & I. 90 & $7.6 \mathrm{I}$ & 3 I. 44 & 50.57 & $49 \cdot 43$ \\
\hline 2299 & $3 \cdot 46$ & 7.07 & 9.00 & 0.82 & 8.87 & $27 \cdot 4^{2}$ & 49.64 & 50.36 \\
\hline 2300 & 3.86 & $7 \cdot 31$ & $8.5^{8}$ & $\ldots$ & I0. 24 & 32.85 & $55 \cdot 95$ & 44.05 \\
\hline 2303 & $4 \cdot 16$ & 6.56 & $5 \cdot 76$ & 0.60 & I 2.85 & 20.95 & $44 \cdot 40$ & 55.60 \\
\hline 2293 & 4.84 & $0.8 \mathrm{I}$ & 5.10 & 0.78 & I. 40 & 27.60 & $39 \cdot 70$ & 60.30 \\
\hline 2296 & 3.17 & 4.60 & $3 \cdot 5^{8}$ & $\ldots$ & 5.93 & 36.88 & 50.32 & 49.68 \\
\hline 2297 & 3.40 & $4 \cdot 34$ & $3 \cdot 5^{8}$ & $\ldots$ & 5.47 & 36.54 & $49 \cdot 32$ & 50.68 \\
\hline 2298 & $3 \cdot 47$ & $4.4 \mathrm{I}$ & 3.50 & $\ldots$ & $5 \cdot 3^{8}$ & 34.80 & $47 \cdot 5^{2}$ & $5^{2} \cdot 4^{8}$ \\
\hline & & & & Blue. & & & & \\
\hline 2294 & $5 \cdot 58$ & 9.II & $\ldots$ & $1.5 I$ & 13.13 & 18.78 & $39 . \infty 0$ & 61.00 \\
\hline 2302 & 3.16 & $14 \cdot 36$ & $\ldots$ & I. 47 & 25.03 & 25.05 & $55 \cdot 3^{8}$ & 44.62 \\
\hline 2305 & $3 \cdot 78$ & II. 28 & $\ldots$ & 0.53 & I 8.76 & 19.04 & 42.25 & $57 \cdot 75$ \\
\hline 2378 & 4.19 & 13.76 & $\cdots$ & 0.83 & $25 \cdot 5^{2}$ & 18.09 & 48.11 & 51.89 \\
\hline 2380 & 3.79 & $17 \cdot 39$ & $\ldots$ & 0.77 & 26.15 & 18.80 & $49 \cdot 70$ & 50.20 \\
\hline 2382 & $3 \cdot 57$ & 2 I. 87 & $\cdots$ & 0.87 & 26.77 & 30.34 & $62.9^{8}$ & 37.02 \\
\hline 2301 & 3.65 & 14.69 & $\ldots$ & $\begin{array}{l}\text { PURPLE } \\
22.66\end{array}$ & 5.28 & 19.71 & 51.28 & $4^{8} \cdot 7^{2}$ \\
\hline 2304 & 3.87 & 16.56 & $\ldots$ & $25 \cdot 50$ & 7.69 & 19.66 & 57.22 & $42 \cdot 78$ \\
\hline \multicolumn{9}{|c|}{ COPY PAPERS. } \\
\hline 2306 & $5 \cdot 40$ & 2.73 & 2.53 & 6.13 & 3.82 & 27.87 & 45.82 & 54.18 \\
\hline $229 I C$ & $4 \cdot 34$ & I. 53 & $\ldots$ & $4 \cdot 42$ & $3 \cdot 74$ & 30. I 5 & 43.10 & 56.90 \\
\hline 2292 & $3 \cdot 45$ & 2.26 & $\ldots$ & $6.5^{2}$ & 6.25 & 37.07 & 63.80 & 36.20 \\
\hline 2295 & 4.83 & 2.64 & $\ldots$ & I I $\cdot 5$ I & 4.60 & 25 . I & 46.05 & 53.95 \\
\hline $229 \mathrm{I} d$ & 4. I6 & $4 \cdot 50$ & $\ldots$ & 6.32 & 2.48 & 34.96 & 48 . I I & 51.89 \\
\hline
\end{tabular}

The kind and relative amounts of the components of the ink are important factors in the working qualities of a typewriter carbon paper. The data obtained in Table II are useful in arriving at a general idea of the various ingredients used for ink, their relative proportions and those combinations which appear to give the best results in working qualities. The influence of the kind and state of division of the carbon and other pigments used, of the kind of oil or wax, of varying kinds and amounts of dyes, etc., can be determined only by an examination of a very large number of papers, the variation being so great that it is not now possible to present a formula for the composition of a standard ink. To illustrate the variation, the amount of ink in one of the best papers amounts to 63 per cent. and in another paper equally as good, so far as working qualities, there is but 43 per cent. of ink, while the average is between 
5o ancl 55 per cent. () course, in deciding between two papers that ditier so widely as these mentioned, the important question is as to which has the larger anount of inl arailable for writing purposes.

Ior the base of the ink, parafin waxes of rather high melting points are very generally etmployed, although not exclusively so. Pigments like Irustian blue and lampblack and dyes such as methylene blue and methy violet appear in many of the papers, while in others the same or hetter results are obtained by other combinations. The percentage figures shown in lable II are of value nainly in correlation with the results shown in Tables I and III.

Mithit. Separation of the ink from the paper was difficult to accompiish. Several methods were tried. Boiling water, acids and alkalies poured over the paper alter it had been cht into strips, separated the ink effectually, but disintegrater the paper. Jithyl ether or petroleum ether cif low boiling point would not dissolve the wax of the ink so that it might he filtered. Petrolemm ether of higher and definite boiling point was very hard to obtain, as tern gallons of $66^{\circ}$ gasoline yielded but three quatts of a product boiling between $70^{\circ}$ and $90^{\circ}$, and this was very hard to evaporate of completely as well as being dangerous to store and handle. l'ure benzene, boiling point $8 I-2^{\circ}$, was finally adopted as the solvent, but it haid to be prepared free from alcohol and water, so that dyes would not be affected. The henzene was therefore treated in the way ordinarily used for cleansing ether, by shaking repeatedly with water and then allowing it to stand for several day's orer metallic sodium.

A weighed portion of the paper, cut into narrow strips and put in a beaker, wa comed witis the prepared benzene, heated quickly on the steam-bath with shaking and poured through a weighed porcelain Gooch crucible, using suction. Three or more applications of the solvent removed all of the ink, possibly with the exception in sone cases of a trace of dye. The filtrate, which was clear and usually colorless or pale yellow, was received in a veighed beaker, the solvent evaporated off, and the weight of the wax determined directly. The residue was afterwards examined to deternine its properties, such as melting point, specific gravily, saponification value and iodine number.

Both the Cooch crucible, containing the piginent and dye, and the residue of paper were dried and weighed. 'lhey were then treated with thot alcohol of 95 and 70 per cent. strengths, and the Gooch in addition was thoroughly washed with hot water. Cooch and paper were again dried and weighed, the total loss being the weight of the dye. The solution of the dye itn alcohol and water, thus obtained, was examined to determine the kind of dye employed. The weight of the paper, which was now perlectly clean, was recorded and the weight of total ink found by difierence. The results, expressed as per cents, are found in 'lable II. 
The Gooch crucible was then treated several times with hot alkalies and acids and the dried residue, if any, weighed as carbon. If, however, on burning off the carbon, an appreciable amount of ash still remained, the presence of insoluble pigments was shown, the kind and quality of these being determined by an examination of the ash of the whole paper.

Moisture and ash were determined on another portion of the sample; moisture at $100^{\circ}$ to constant weight and ash at a low red heat. The ash was examined qualitatively and quantitatively for metals such as iron, chromium, aluminum, zinc, calcium, magnesium, etc., and for phosphoric, sulphuric, silicic acids, etc.

TABLE III,-TESTS OF WRITING.

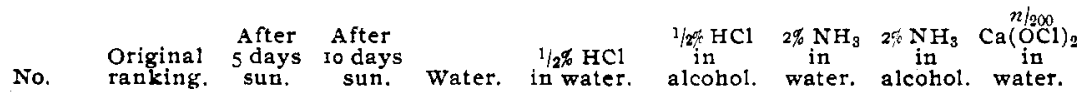

RECORD PAPERS: BLACK.

$\begin{array}{lccccccccc}2288 & \text { I } & 2 & 3 & 2 & 2 & 2 & 4 & 2 & 3 \\ 2289 & 2 & 3 & 4 & 3 & 3 & 3 & 6 & 3 & 3 \\ 2290 & 5 & 6 & 6 & 6 & 6 & 6 & 8 & 6 & 6 \\ 2377 & 2 & 3 & 5 & 4 & 4 & 4 & 5 & 3 & 3 \\ 2379 & 2 & 3 & 5 & 4 & 5 & 5 & 5 & 3 & 3 \\ 2381 & 2 & 3 & 5 & 6 & 4 & 4 & 6 & 3 & 3 \\ 2291 a & 1 & 2 & 3 & 2 & 3 & 3 & 6 & 3 & 3 \\ 2291 b & 1 & 2 & 3 & 2 & 3 & 3 & 6 & 3 & 3 \\ 2299 & 4 & 5 & 6 & 5 & 6 & 5 & 7 & 5 & 5 \\ 2300 & 1 & 3 & 4 & 3 & 4 & 3 & 7 & 3 & 3 \\ 2303 & 2 & 2 & 3 & 5 & 3 & 3 & 5 & 3 & 3 \\ 2293 & 2 & 3 & 5 & 3 & 3 & 4 & 5 & 4 & 3 \\ 2296 & 2 & 3 & 5 & 3 & 3 & 4 & 5 & 3 & 3 \\ 2297 & 2 & 4 & 6 & 3 & 4 & 4 & 5 & 3 & 4 \\ 2298 & 4 & 3 & 5 & 5 & 4 & 5 & 4 & 5 & 5 \\ 2294 & 4 & 5 & 7 & 5 & 5 & 6 & 8 & 8 & 5 \\ 2302 & 2 & 3 & 3 & 3 & 3 & 3 & 4 & 3 & 2 \\ 2305 & 3 & 4 & 6 & 4 & 4 & 4 & 5 & 5 & 4 \\ 2378 & 2 & 4 & 5 & 3 & 4 & 4 & 6 & 4 & 4 \\ 2380 & 2 & 4 & 6 & 5 & 4 & 4 & 8 & 4 & 3 \\ 2382 & 2 & 3 & 4 & 4 & 4 & 3 & 6 & 4 & 3 \\ 2301 & 2 & 7 & 8 & 3 & 5 & 6 & 7 & 6 & 3 \\ 2304 & 3 & 6 & 8 & 4 & 5 & 7 & 6 & 5 & 4 \\ 2306 & 3-5-8 & 4-5-8 & 5-6-9 & 5-5-9 & 4-5-10 & 4-5-10 & 6-6-10 & 3-4-9 & 6-6-7 \\ 2291 C & 2-2-6 & 2-3-7 & 4-4-8 & 6-6-7 & 3-4-5 & 7-7-8 & 7-8-8 & 8-8-9 & 5-6-7 \\ 2292 & 6-6-8 & 6-7-9 & 7-8-10 & 7-8-8 & 5-6-7 & 8-9-9 & 7-8-8 & 7-8-8 & 6-7-8 \\ 2295 & 3-5-6 & 3-5-7 & 6-5-8 & 5-6-9 & 6-7-9 & 8-7-10 & 7-7-9 & 7-4-8 & 5-5-7 \\ 2291 d & 3-5-5 & 2-4-6 & 3-4-7 & 6-7-9 & 5-5-9 & 8-7-9 & 8-8-9 & 8-5-9 & 6-6-7\end{array}$

The writing used for these tests was made with a fresh sheet of the 
copy paper. It was first rated on a scale of ten according to the following outline:

r. Clear, strong.

2. Almost as good as $\mathbf{r}$.

3. Not very clear nor strong, or strong but some blurred.

4. Between 3 and 5.

5. Lighter than 4 but still clear, or strong but much blurred,

6. Between 5 and 7 .

7. Very light but clear, or strong and very badly blurred.

8. Between 7 and 9 .

9. Very pale and weak, or much blurred, letters not distinct.

Io. Very pale, almost illegible, or very much blurred, almost illegible.

It may readily be seen that characters can grade off from those that are clear, strong and perfectly satisfactory in either of two directions. They may become fainter, and thus fail in strength and clearness, or they may become heavier and blurred. The figures in Table III show that this is a ready means of separating the good papers from the pooter ones, all of the impressions having been made on the same machine by the same operator and using the same quality of paper.

After rating the original writing as above, strips of the same were exposed to sunlight for ten days and to the various wet reagents for one hour, dried and again rated according to the following scale:

I. Unaffected.

2. Very slightly affected, just distinguishable.

3. Slightly affected.

4. More than 3.

5. Much affected.

6. Still more than 5 .

7. Very badly affected.

8. Almost effaced, letters distinct.

9. Almost effaced, letters indistinct.

Io. Completely effaced.

The method of ranking may not be clear from the mere lists above, but the actual scales, composed of writing classified as the scales indicate, made it possible to rank the samples with comparative ease. In the case of copy papers, strips of the original writing, of the writing that had served for copy and the copy itself were exposed to the same tests and separately ranked. In Table III the three figures appearing in each column for copy papers give the rating of original, copied writing and copy in the order named.

For the sunlight test, the exposure was made under glass in a picture frame, and the number of days recorded included only those of direct sunlight. The following wet reagents were used:

I. Water at room temperature.

2. 0.5 per cent. $\mathrm{HCl}$ in water.

3. 0.5 per cent. $\mathrm{HCl}$ in alcohol. 
4. 2 per cent. ammonia in water.

5. 2 per cent. ammonia in alcohol.

6. N/200 calcium hypochlorite.

Very delicate reagents were found to give better comparative results, and for the same reason the time of exposure was limited to one hour. Strips of the paper in Erlenmeyer flasks were covered with the reagent and the immediate effect as well as that after each fifteen minutes was noted. Only the final result after an hour's action is recorded in the table. It is noteworthy that water, which with the exception of the copy papers does not affect the ink as a solvent, does remove it mechanically to a material extent, and with the other reagents also the largest part of their effect is due to the displacement of the ink bodily, and not to any chemical or solvent action.

Beginning with Table III the papers which show the best writing qualities and the most resistant ink are numbers $2288,2289,229 \mathrm{I} a, 229 \mathrm{I} b, 2300$ and 2303 among the black record class; numbers 2302 and 2382 of the blue record; number $229 \mathrm{I} C$ among the copy papers and possibly number 230 I of the purple record. Numbers 2288, 2289, 2300 and 2303 from Table I have the best paper backing but 2303 does not give a good stretch test and from Table II has but 44 per cent. of ink, indicating that it would be short-lived. Number 2288 has also a small quantity of ink. The choice lies then between numbers 2289 and 2300 , made by different manufacturers of established high standing, number 2300 having the advantage of being a feather weight paper with exceptionally high tensile strength and stretch.

The purple record papers were made by the same firm and are of nearly equal quality, the advantage being slightly in favor of $230 \mathrm{r}$ in the tests of the writing and the strength of the paper foundation, and with the disadvantage of having somewhat less ink. Of the blue record papers, number 2382 though of lighter weight has the greater strength and much more available ink. Of the copy papers, number $229 \mathrm{I} c$ has very high strength and stretch but unfortunately only a small amount of ink. For some of the tests of writing number 2306 stands higher than 229 I C and the strength of the paper is greater, but the amount of ink is possibly too low to give long service.

BUREAU OF CHEMISTRY,

WASHINGTON, D. C.

\section{GLUTEN FEEDS-ARTIFICIALLY COLORED.}

BY EDWARD GUDEMaN.

Received July 20, Igo8.

Gluten feeds are the by-products obtained in the starch, glucose, corn sirup and starch-sugar industries. In the process of manufacture the 